\title{
Cone opsins and response of female chamois (Rupicapra rupicapra) to differently coloured raincoats
}

\author{
S. Raveh • W. F. D. van Dongen • C. Grimm • P. Ingold
}

Received: 10 June 2011 /Revised: 5 March 2012 / Accepted: 12 March 2012 /Published online: 18 April 2012

(C) Springer-Verlag 2012

\begin{abstract}
Alpine species are often exposed to intense levels of human recreational activities. Exactly how human disturbances influence the behaviour of these species is still open to much debate. For example, little is known regarding how the colourful clothing often worn by tourists influences the behaviour of animals. Tourists wearing colourful clothing may be more conspicuous to local wildlife and thus cause more disturbances. We therefore investigated this question in female chamois (Rupicapra rupicapra) in the Swiss Alps. We firstly investigated, via a morphological and an immunohistochemical approach, whether chamois are likely to have colour vision and would therefore be more likely to respond to different coloured clothing. We detected evidence of two cone types-short-wavelength-sensitive
\end{abstract}

Communicated by C. Gortázar

S. Raveh $\cdot$ P. Ingold

Ethology and Nature Conservation, Department of Zoology,

University of Bern,

Länggassstrasse 27,

3012 Berne, Switzerland

S. Raveh $(\varangle) \cdot$ W. F. D. van Dongen

Konrad Lorenz Institute of Ethology, Department of Integrative

Biology and Evolution, University of Veterinary Medicine,

Vienna, Austria

e-mail: shirleyraveh@hotmail.com

C. Grimm

Lab for Retinal Cell Biology, Department of Ophthalmology,

University of Zurich,

Wagistrasse 14,

8952 Schlieren, Switzerland

Present Address:

P. Ingold

Färichweg 1,

3038 Kirchlindach, Switzerland cones (S-cones, JH 455) and middle-wavelength-sensitive cones (M-cones, JH492) in the chamois retina - suggesting that chamois have dichromatic vision, similar to other ungulates. Secondly, via behavioural assays where a person wearing one of three coloured coats commonly worn by tourists (red, yellow and blue) approached a female chamois, we show that neither the alert and flight initiation distance nor the site of refuge were influenced by the raincoat colour. In addition, behavioural responses of the chamois were neither influenced by animal group size nor the presence of kids nor the time of the experiment. The results suggest that, although chamois possess colour vision, they do not react more strongly towards conspicuous colours worn by hikers. We discuss our results in light of what is already known about chamois biology and suggest implications for future studies.

Keywords Tourism · Alert distance $\cdot$ Flight initiation distance $\cdot$ Clothing $\cdot$ Colour vision $\cdot$ Chamois $\cdot$ Rupicapra rupicapra

\section{Introduction}

In the past decades, tourism has increased in the Alpine Arch of Europe. This rising popularity of recreation (tourism and outdoor leisure sports) in mountain regions often results in a conflict between human activities and local wildlife (Arlettaz et al. 2007; Ingold 2005; Stankowich 2008; Taylor and Knight 2003). Many studies have shown, for example, that alpine animals such as marmots (Marmota marmota), ibex (Capra ibex) and chamois (Rupicapra rupicapra) react strongly to tourist activities, resulting in short and long-term consequences. These detrimental effects include loss of grazing time, abandonment of high quality pastures and increased energy consumption, which leads to 
a reduction in body condition and reproductive success (Enggist-Düblin and Ingold 2003; Gander and Ingold 1997; Hamr 1988; Hüppop 1995; MacArthur et al. 1982; Schaal and Boillet 1992; Schnidrig-Petrig 1994; Zeller 1991; Zimmerli 1993). These negative effects could be avoided by reducing the encounter rate between human and wildlife or adapting the tourists' behaviour.

There are several strategies to minimise the impact of human presence on local wildlife (Keller, 2001). However, it is firstly essential to identify the factors associated with leisure activities that elicit responses in wild animals. For example, several studies have shown that animals react more strongly when approached off trail and from above than from below (bighorn sheep: Hicks and Elder 1979; marmots: Mainini et al. 1993; chamois: Zeller 1991). Furthermore, animals such as wild sheep (Ovis canadensis canadensis) (MacArthur et al. 1982; Martinetto and Cugnasse 2001) and marmots (Mainini et al. 1993) have been shown to exhibit an increased reaction when a person was accompanied by a dog. Similarly, the flight responses of female chamois were longer and more intense when exposed to loud-speaking, as opposed to silent, hikers (Kobelt 2004).

In recent times, sportswear has tended to become more colourful, with brighter designs (such as yellows and reds). Bright colouration is known to increase the conspicuousness of objects in relation to drab backgrounds, which are typical of natural environments (e.g. Endler 1993; Doucet et al. 2007). This may result in an augmented conspicuousness of alpine tourists, which in turn may have a negative impact on local wildlife by reducing the chances that humans can pass the animals without causing a disturbance and by increasing the time that tourists are visible during the animal's flight response. In contrast to tourists, clothing worn by hunters is typically drabber and designed to decrease conspicuousness at least during the still hunt. However, it is often unknown whether the game animals can indeed perceive colour differences. Despite these predictions and the possible negative consequences of increased conspicuousness of tourists on wildlife, studies investigating the influence of brightly coloured clothing worn by tourists on wildlife behaviour are lacking.

An important first step in exploring the effects of colourful clothing on wildlife is to confirm that the species indeed has the capacity to perceive colour differences. Immunohistochemistry allows a straightforward approach to test whether eyes at least have the photoreceptor cells necessary to detect colour (e.g. Hemmi and Grünert 1999; Dkhissi-Benyahya et al. 2001; Arrese et al. 2003a). Whereas rods are responsible for perceiving differences in brightness and for monochromatic vision in low light levels (Kaskan et al. 2005), two or more cones are necessary to enable colour vision. Most mammals possess two cone types, one that is sensitive to short-wavelengths (blue) and one that is sensitive to mid-wavelengths (green) and therefore have dichromatic colour vision (Jacobs 1981; Jacobs 2009). In contrast, trichromatic colour vision, which requires three cone-types, is restricted to hominoids, Old World monkeys and some New World monkeys (Jacobs 1993).

Chamois are a common ungulate species inhabiting rocky and steep mountain areas up to 3,000 $\mathrm{m}$ above sea level. In some areas in the central Alps, chamois are exposed to intense recreational tourism activities, such as hiking, biking, riding/ trekking and cross-country skiing. Past studies have shown that increased human activities in chamois habitat can negatively impact on chamois behaviour (Enggist-Düblin and Ingold 2003; Gander and Ingold 1997; Hamr 1988; Schaal and Boillet 1992). In contrast, it remains unknown whether the colourful clothing often worn by hikers makes them more conspicuous to chamois. To test this idea, it is necessary to show (1) that chamois have colour vision and (2) that they respond differently to hikers wearing differently coloured clothing. We therefore firstly used an immunohistochemical approach, by staining the retina with two cone-specific antibodies, to ascertain whether chamois have at least a dichromatic vision system. Although ungulates typically possess dichromatic vision (e.g. domestic goat, Capra aegagrus hircus: Siemers et al. 1999; sheep, Ovis aries: Munkenbeck 1982; domestic pig, Sus domesticus: Koba and Tanida 1999; fallow deer, Dama dama and white-tailed deer, Odocoileus virginianus: Jacobs et al. 1994, Birgersson et al. 2001; horse, Equus ferus caballus: Carroll et al. 2001), no data currently exist for colour vision in chamois. Secondly, by using a field experiment, we investigated whether an approaching person wearing differently coloured clothing had an influence on the alert and flight responses and the site of refuge of female chamois. We predict that conspicuous coloured clothing would result in (1) an earlier alert response, (2) a longer flight initiation distance and (3) a longer flight to the site of refuge than drabber coloured clothing.

\section{Material and methods}

Morphological and immunohistochemical analysis

Four enucleated eyes from a dead male and female chamois were examined in December 2002/January 2003. Both animals died via authorised culling by a gamekeeper. For light microscopy examination, two enucleated eyes (retrieved on-site immediately after the death of the animal) from different animals were immersed in $2.5 \%$ glutaraldehyde in $0.1 \mathrm{M}$ cacodylate buffer at $\mathrm{pH} 7.3$ for the transport to the lab. The cornea and lens were removed, and the eyecup was further incubated in $2.5 \%$ glutaraldehyde in $0.1 \mathrm{M}$ cacodylate buffer with $\mathrm{pH} 7.3$ at $4{ }^{\circ} \mathrm{C}$ for postfixation (overnight). The tissue was cut to prepare regions of interest, washed in 
cacodylate buffer and incubated in osmium tetroxide (1\%) for $1 \mathrm{~h}$. The tissue was embedded in Epon 812. Sections (0.5 $\mu \mathrm{m})$ were prepared and counterstained with methylene blue.

For immunohistochemical analysis, the two other eyes were enucleated, the lenses were removed and the remaining vitreous bodies, together with the retinas, were preserved in a $4 \%$ paraformaldehyde solution $\left(\mathrm{pH} 7.4\right.$ ) for $4 \mathrm{~h}$ at $4{ }^{\circ} \mathrm{C}$. Eyecups were cut in coronal cross sections, washed and kept overnight at $4{ }^{\circ} \mathrm{C}$ in PBS. The retinas were then isolated and prepared as whole mounts for immunohistochemical analysis.

A standard method was chosen, implementing specific antibodies that recognise short- and medium-wavelength opsins to determine the presence of different cone types in the eye of the chamois. This technique has previously been used in many similar studies (Wikler et al. 1996; Hemmi and Grünert 1999; Dkhissi-Benyahya et al. 2001; Arrese et al. 2003a).

Nonspecific binding sites were blocked by incubation in PBS containing $0.1 \%$ Triton X100 and $10 \%$ normal goat serum (NGS). Primary antibodies (JH492, 1:4000; JH455, 1:4000) were then applied for $3 \mathrm{~h}$ at room temperature in PBS containing $0.1 \%$ Triton X100 and $3 \%$ NGS. JH492 antibody recognizes middle-wavelength-sensitive cone opsin (M-cones), whereas JH455 is specific for shortwavelength sensitive cone opsin. Both antibodies were raised against the respective human proteins (Chiu and Nathans 1994) and recognized MWL and S-cone opsins in a variety of species including the mouse (Mus musculus: Chiu and Nathans 1994), Syrian hamster (Mesocricetus auratus: Glosmann and Ahnelt 2002), rabbit (Oryctolagus cuniculus: Hack and Peichl 1999), marsupials (Arrese et al. 2003b), horses (Sandmann et al. 1996) and primates (Martin and Grünert 1999). Peanut agglutinin (PNA, 1:250; Sigma) was used as a general cone marker (Unoki et al. 1988). After staining, the retinas were washed three times in PBS containing $0.1 \%$ Triton X100. Secondary rabbit antibodies (1:250, Cy3 coupled; Jackson ImmunoResearch) or peanut agglutinin were applied for $2 \mathrm{~h}$ at room temperature in PBS containing $0.1 \%$ Triton X100 and $3 \%$ NGS. Retinas were washed three times in PBS containing $0.1 \%$ Triton X100 before they were transferred to slides and examined by fluorescent light microscopy (Axioplan, Carl Zeiss AG, Feldbach, Switzerland). Images were taken using a digital camera (AxioCam, Carl Zeiss AG, Feldbach, Switzerland).

\section{Behavioural assays}

Study area and animals The experiment was carried out on the northwest flank of the Augstmatthorn game reserve at an altitude of $1,700 \mathrm{~m}$ above sea level (Bernese Oberland, Switzerland: $46^{\circ} 45^{\prime} \mathrm{N}, 7^{\circ} 55^{\prime} \mathrm{E}$ ). Behavioural observations were conducted from June to August 2003. The area is characterised by steep slopes of limestone rocks and screes, intersected by rocky gullies running down the slopes. A large number of female chamois with kids can be found at the northwest side of the Augstmatthorn on sunny days (Ruckstuhl and Ingold 1998). Natural licks exist in the gullies, which are regularly visited by chamois to ingest the mineral-rich water coming out of the rock or marl. The licks possess a high level of sodium (Marbacher 1989), which is important for bone structure, growth and digestion (Robbins 1993). Access to these licks is therefore essential for suckling females during lactation. One such lick was chosen as the study site $\left(46^{\circ} 45^{\prime} 46.3^{\prime \prime} \mathrm{N}, 7^{\circ} 55^{\prime} 14.1^{\prime \prime} \mathrm{E}\right)$, due to the ease of observation (no dense vegetation or obstructions to block the view of the lick) and the reliable availability of water (Marbacher 1989). The lick is situated below a rarely used hiking trail that winds along the ridge of the slope. Only three people were observed using this trail during the experimental time.

Data collection Experiments were conducted on clear, sunny days between 0600 hours to 1600 hours. To minimise the effects of group dynamics influencing vigilance behaviour of the focal individual, experiments were only conducted when a maximum of three other adult animals were present in the focal gully. We tested the responses of chamois to raincoats that were either bright yellow, bright red or azure blue (red hue: $1^{\circ}$, saturation: $83 \%$, brightness: $95 \%$; yellow hue: $57^{\circ}$, saturation: $72 \%$, brightness: $97 \%$; blue hue: $195^{\circ}$, saturation: $78 \%$ and brightness: $91 \%$ ). The colours of the raincoats were chosen because they were commonly worn by hikers in the region (S. Raveh: personal observation). An experiment consisted of a person, wearing one of the three raincoats approaching a chamois at the lick from a defined starting point ( $216 \mathrm{~m}$ from the lick). The trail curved around the lick (distance between path and lick, 45-216 m). The approach by the investigator to the focal animals was therefore indirect (Fig. 1). Any chamois at the lick would perceive the approaching person against a light blue sky background. The person approached at normal walking pace, and the same person conducted all the trials alone. The colour of the raincoat worn in each experiment was chosen randomly and combined with navy blue trousers (blue coloured trousers were observed to be often worn by hikers in the region). When the focal animal first raised its head and looked towards the investigator, the distance separating the two was measured in metres (alert distance (AD)). If a nonfocal female showed an alert or escape behaviour, before the focal female, then the experiment was terminated. Experiments were also terminated in cases where the focal animal took flight before the trial commenced. The person then resumed walking on the trail until the animal took flight. At this time, flight initiation distance (FID) was measured, defined as the distance between the focal animal and the person at the moment the animal took 


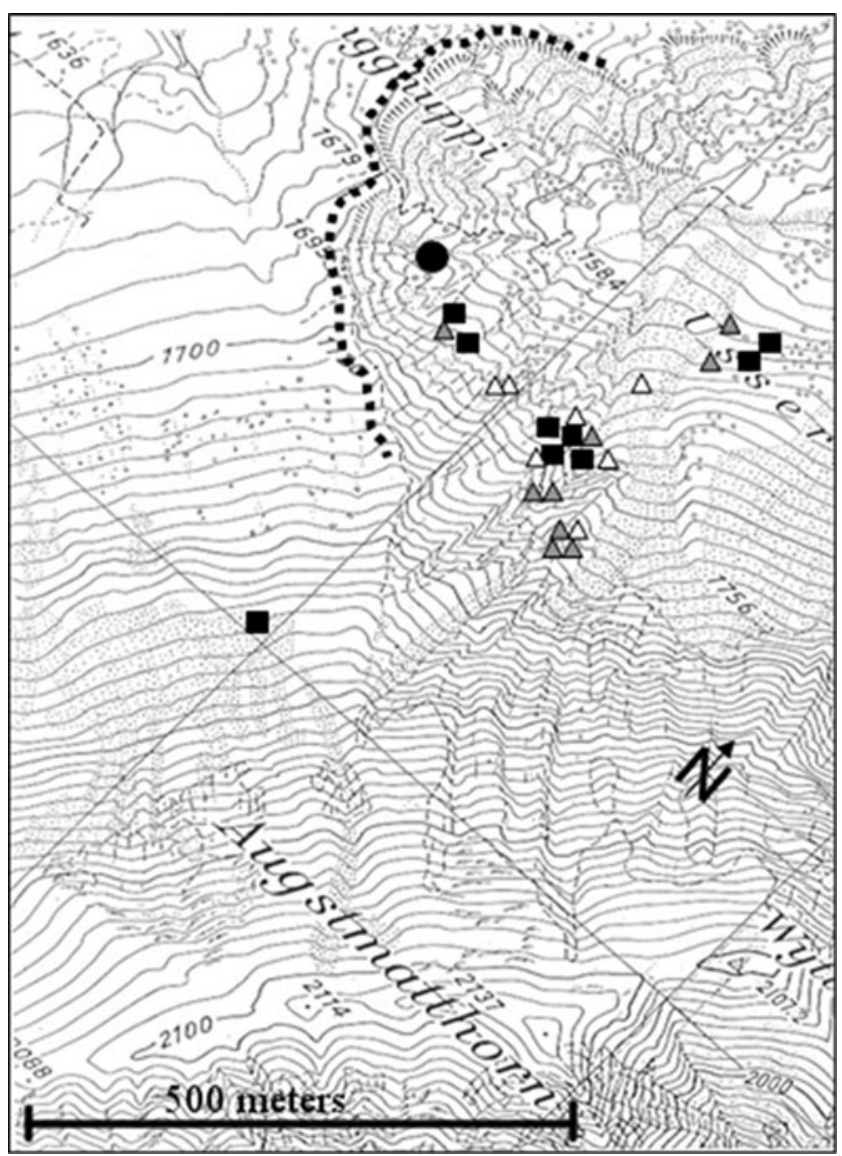

Fig. 1 Morphology of the chamois retina. a Semithin section of the outer retina. Asterisk photoreceptor inner segments resembling cones. $O N L$, outer nuclear layer; $P I S$, photoreceptor inner segments; $P O S$, photoreceptor outer segments; $R P E$, retinal pigment epithelium. b Magnification of an area shown in a. Arrow, rod outer segment with discs containing rhodopsin; arrowhead, cone outer segment with discs containing cone opsin. Abbreviations and symbols as in a. c Semithin section through all layers of the retina of chamois. TAP, tapetum; INL, inner nuclear layer; $G C L$, ganglion cell layer; $N F L$, nerve fibre layer. Other abbreviations as in a. Scale bars 50 (a), 25 (b) and $100 \mu \mathrm{m}$ (c)

flight (Cederna and Lovari 1985). Both AD and FID were measured with a laser range finder (Leica $7 \times 42$ BDA, GEOVID). After the animal took flight, the investigator visually tracked the animal and then, after a 10 -min period, marked its site of refuge on a 1:25000 map of the study site. The refuge of the animals was difficult to locate because of the hilly terrain. In five cases, the observer lost track of the animals during the flight. The positions of the remaining 25 individuals were recorded on the map.

For each trial, the investigator recorded the time of the day, the number of animals at the surrounding licks and whether the focal females were accompanied by kids (all females had given birth at this point of time). We waited a minimum of $2 \mathrm{~h}$ between trials (Marbacher 1989). Trials were conducted only on sunny days in order to maintain a constant reflection of the coloured raincoats and when the wind was blowing in the direction of the investigator to prevent odour cues. We excluded chamois younger than 2 years from our analyses because the flight distance in older animals is higher than that in subadult chamois (Patterson 1988). Age was determined by the growth rings of the horns (Schröder and Elsner-Schack 1985). Ten trials per coat colour were conducted.

Statistical analysis The data were analysed with SPSS 17 statistical software. Kolmogorov-Smirnov test were used to test for the normality of the data. Levene's test was used to test for deviations from homogeneity of variances. Nonparametric tests were used for analysing the AD data, since these data were not normally distributed. In contrast, the FID data were normally distributed. The differently coloured raincoats, experimental time (morning or afternoon), group size and the presence of kids were treated as independent variables; whereas the alert distance and the flight initiation distance were the two dependent variables. To quantify habituation effects, we tested whether the number of trials already conducted at the lick was associated with the AD and FID of the focal individuals by using Spearman's rho and Pearson correlations, respectively. The likelihood of testing an individual twice was small due to the large number of females present in the region (in 2003: on average $=78, n \max =87$ ) (Willisch et al. unpublished data). In addition, data collection only occurred on sunny days, which were often separated by days of high cloud cover or fog. Sampling, therefore, was scattered over the 3-month period, rendering it unlikely that we constantly resampled a small number of chamois. Trials were also conducted at least $2 \mathrm{~h}$ apart from each other, and this decreased the likelihood of measuring a female twice since females generally did not stay at a lick for such long periods (10 min-1 h; Raveh, personal observation). Lastly, we found no effects of habituation (see below), suggesting that we did not repeatedly test the same subset of animals.

\section{Results}

Morphological and immunohistochemical analysis

Morphological sections of the central temporal retina revealed the presence of two photoreceptor cell types in the outer retina (Fig. 2a): cells with a long and thin outer segment and cells with a thicker, cone-like structure (stars in Fig. 2a, b) in the layer of the photoreceptor inner segments (PIS) and a shorter outer segment. These cells were most likely rods and cones, respectively. Using a higher magnification, we could clearly distinguish the two photoreceptor types and also detected the discs (arrow for rod discs, 


\section{a}

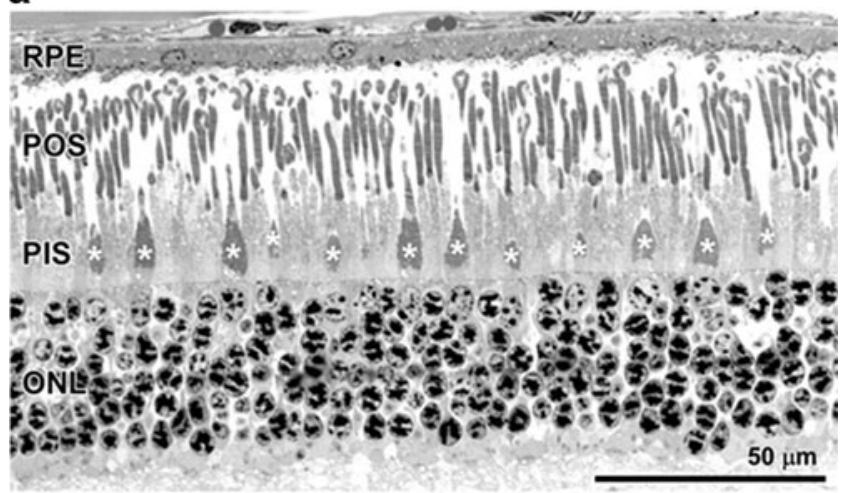

b
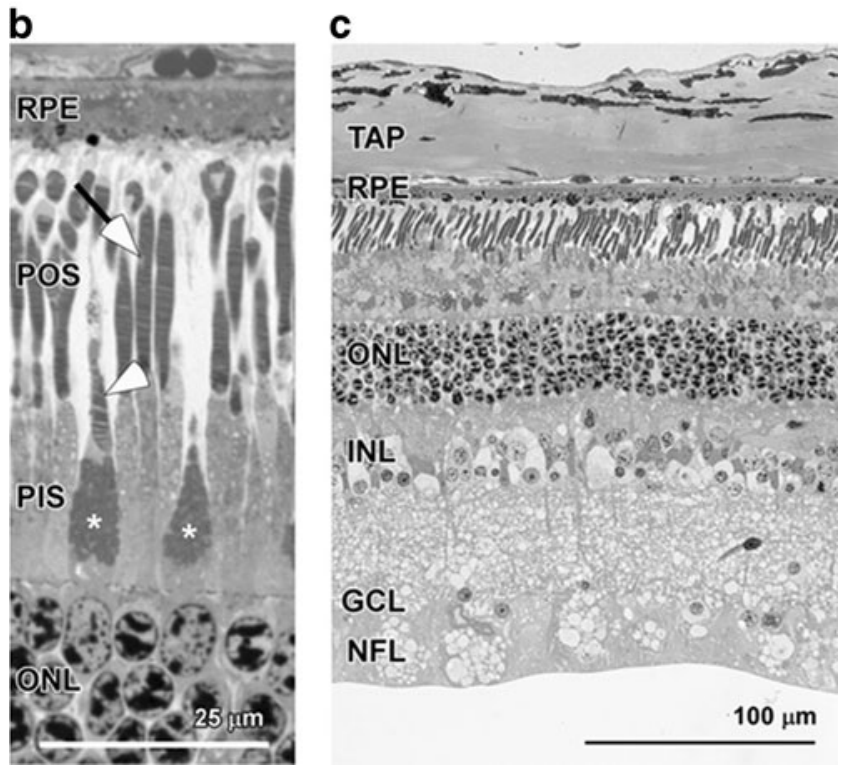

Fig. 2 Selective staining of cone photoreceptors in the chamois retina. Immunofluorescence of retinal flatmounts with peanut agglutinin (green) and with antibodies raised against short-wavelength cone opsin (JH 455, red) (a) or middle-wavelength cone opsin (JH 492, red) (b), respectively. The orange colour indicates co-localization. White arrows correspond to cone outer segments that were positive for peanut agglutinin only. Red arrows correspond to cone outer segments that were positive for both peanut agglutinin and short- (a) or middlewavelength (b) cone opsins, respectively

arrowhead for cone discs, Fig. 2b) in the outer segments containing the visual pigment. Spacing of cone cells was relatively regular with one cone among roughly ten photoreceptor cells. This distribution was similar in all regions analysed. Apart from photoreceptors, the chamois retina showed normal layering of retinal cells with a nerve fibre layer (NFL), ganglion cell layer (GCL), inner nuclear layer (INL), outer nuclear layer (ONL) containing five to six rows of photoreceptor nuclei, the retinal pigment epithelium (RPE) and the tapetum (TAP) behind the RPE (Fig. 2c). The spectral reflection of the tapetum during the preparation of the eyes ranged from greenish-blue to yellow (personal observation) as described in sheep (Bellairs et al. 1975). Cell density in GCL and INL was very low (Fig 2), suggesting a strong convergence of information from photoreceptors to ganglion cells, which may point to a rather low visual acuity.

To test the presence of cone photoreceptor cells directly, we used PNA to stain retinal flat mounts. PNA is reported to be a specific marker for cones as it interacts with galactosegalactosamine disaccharides (Blanks and Johnson 1984) and PNA specifically labelled cone, but not rod cells, in a variety of species including fish, rabbit, monkey, human, chicken, guinea pig, mouse, rat and others (Blanks and Johnson 1984; Hageman and Johnson 1986; Krishnamoorthy et al. 2008; Unoki et al. 1988). Staining of chamois retinal flat mounts revealed a high density of PNA-positive cells (white arrows in Fig. 3). Due to the specificity of the PNA marker, these cells are assumed to be cones. Double staining with PNA and antibodies specific for short-wavelength S (blue)cones (staining with JH 455; Fig. 3a) or middle-wavelength M (green)-cones (staining with JH492; Fig. 3b) confirmed the presence of at least two cone types. Antibody signals strictly colocalized with PNA-positive cells (red arrows in Fig. 3a, b) demonstrate that PNA labels cones also in chamois. However, not all cells positive for PNA were positive for one of the two cone-specific antibodies (see "Discussion").

\section{Behavioural assay}

Alert distance We quantified $30 \mathrm{AD}$ of focal females during the field season. A median of three females (interquartile range (IQR), $2-4 ; n=30$ ) was observed in the focal gulley. Offspring was absent in 16 cases; whereas in the remaining 14 cases, at least one kid was present. The median $\mathrm{AD}$ for blue raincoats was $214 \mathrm{~m}$ (IQR 213.5-215.2 m; $n=10$ ), for yellow $213.5 \mathrm{~m}$ (IQR 208.8-216 m; $n=10$ ) and for red 216 (IQR 211.5-216 m;
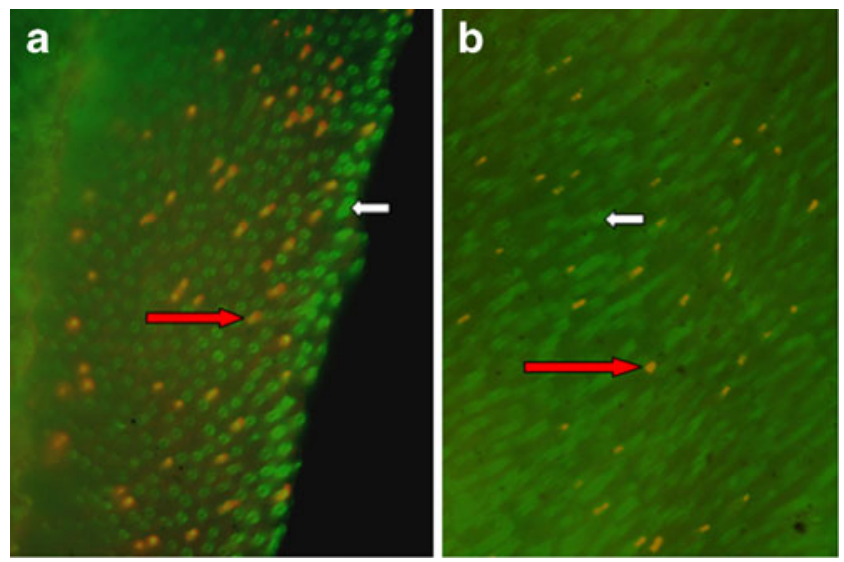

Fig. 3 Distribution of the chamois after the animals took flight from the salt lick (indicated by the black circle) after being exposed to a hiker wearing coloured coats on the hiking trail (dotted line). The various symbols represent that position of refuge of chamois exposed to red raincoats (white triangle), yellow raincoats (black square) and blue raincoats (grey triangle) 
$n=10$ ). The AD was not affected by raincoat colour (KruskalWallis test $\left.\chi^{2}=1.23, d f=2, p=0.54\right)$; by the group size at the lick (Kruskal-Wallis test $\chi^{2}=5.17, d f=4, p=0.27$ ) or by the presence of an offspring at the focal lick (Kruskal-Wallis test $\left.\chi^{2}=1.47, d f=1, p=0.22\right)$.

Flight initiation distance During the field season 30 FIDs were quantified. The average FID in response to a hiker who was wearing a yellow raincoat was $125.3 \pm 12.9 \mathrm{~m}$ (mean \pm $\mathrm{SE})($ median $=135, \mathrm{IQR}=80.2-163.5 \mathrm{~m})(n=10)$, a blue raincoat $111.4 \pm 13.5 \mathrm{~m}($ mean $\pm \mathrm{SE})($ median $=95.5, \mathrm{IQR}=$ $78.5-142.2 \mathrm{~m})(n=10)$ and a red raincoat $118.1 \pm 11.6 \mathrm{~m}$ $($ mean \pm SE $)($ median $=123.5, \mathrm{IQR}=81.5-145.5 \mathrm{~m})(n=10)$. The FID was not significantly influenced by the colour of the raincoats, time of data collection, the group size at the lick or the presence of kids (colour: $F_{2,21}=0.089, p=0.91$; presence of kids: $F_{1,21}=0.023, p=0.88$; group size at the lick: $F_{4,21}=0.931, p=0.46$; and experimental time: $F_{1,21}=$ $0.276, p=0.61$ ). Further, we did not detect an effect of colour on FID when merging data for the two putatively conspicuous colours (red and yellow) and comparing responses to these coats together relative to the presumably less conspicuous blue jacket (colour: $F_{1,22}=0.138, p=0.71$; presence of kids: $F_{1,22}=0.064, p=0.80$; group size at the lick: $F_{4,22}=0.936, p=0.45$; and experimental time: $F_{1,22}=$ $0.315, p=0.58$ ).

Position of refuge The site of refuge of the chamois appeared to vary randomly with the coat colour worn by the hiker (red $n=7$, blue $n=9$ and yellow $n=9$; Fig. 1). Five females took refuge in neighbouring gullies, whereas most of the animals were found in a coppice $(n=15)$, another four focal animals were seen in the bottom of the valley and only one female escaped into the adjacent slope (Fig. 1). There was no association between AD and FID and the number of experiments conducted during the 3 months of the data collection (AD: Spearman's rho $=-0.09, p>0.05, n=30$; FID: Pearson correlation $=-0.18, p>0.05, n=30$ ).

\section{Discussion}

We have shown here that the chamois eye possesses both short-wavelength-sensitive and middle-wavelength-sensitive cones, suggesting dichromatic colour vision. This indicates that they are likely to be able to distinguish between dull blue and yellow colours and are probably able to detect hue differences in at least the yellow and blue coats worn during the behavioural experiments (Carroll et al. 2001). Despite this, we found no effects of the different colours worn by the hiker on the alert or flight initiation distance of the chamois. In addition, group size, the presence of kids or the time of day did not influence the chamois escape behaviour. Based on our data, therefore, it appears that the specific colour of clothing worn by tourists is not directly implicated in the flight response of chamois.

Evidence for colour perception in chamois

Several lines of evidence suggest that, despite not responding differently to the different coloured coats, the chamois are able to detect the differences in at least the yellow and blue coats presented during the behavioural experiments (red tends to appear as yellow for dichromatic species; Carroll et al. 2001). Firstly, the histochemical results presented here, coupled with the general pattern of dichromatic vision amongst ungulates (e.g. domestic goat: Siemers et al. 1999; sheep: Munkenbeck 1982; domestic pig: Koba and Tanida 1999; fallow and white-tailed deer: Jacobs et al. 1994, Birgersson et al. 2001; horse: Carroll et al. 2001), strongly suggests that the chamois also possess dichromatic vision. The PNA staining suggested a high density of cones in the retina in the chamois. This was supported by morphological data showing a regular distribution of cells with inner and outer segments characteristic for cones. Antibodies specific for short-wavelength and middlewavelength cone opsin, respectively, confirmed the existence of at least two classes of cone types. However, not all PNA-positive cells were positive for one of the two antibodies. Assuming that PNA exclusively stains cones in the chamois retina as it does in other species including human, monkey, fish, rabbit, chicken, guinea pig, mouse rat and others (Blanks and Johnson 1984; Krishnamoorthy et al. 2008; Hageman and Johnson 1986; Unoki et al. 1988), this result implies that many cones were not recognized by the antibodies used here. The reason for this remains unclear but may include restricted accessibility of the antibodies to the opsin proteins in some of the antibodies to the cones in the flat mounted retinas or some unknown protein modifications preventing the interaction with the antibodies. Alternatively, chamois retinas may contain cone types that express a visual pigment not detected by the antibodies or PNA may stain additional noncone cell classes in the chamois retina.

The presence of colour vision in chamois can only be definitively resolved with further physiological experiments such as the flicker photometric electroretinogram method, which has been conducted on numerous species to conclusively prove dichromatic vision (goat, sheep and cow, Bos primigenius: Jacobs et al. 1998; fallow and white-tailed deer: Jacobs et al. 1994; fox, Vulpes vulpes and dog, Canis lupus familiaris: Jacobs et al. 1993; horse: Carroll et al. 2001). Secondly, independent of their ability to detect colours, it is already known that chamois are able to at least perceive differences in the brightness of colours (Albrecht 
1988). Therefore, they should still have been able to detect the difference in brightness of the different coloured coats. Brightness contrast between an object and its background is known to influence its conspicuousness (Endler 1993). For example, the dark tone of the red coat against a light sky may appear more achromatically conspicuous than the light coloured tone of the blue coat.

In addition to detecting two cone types in the chamois eye, we also found that the eye contains a prominent tapetum lucidum in the back of the eyecup. This reflective structure acts like a mirror, reflecting light back through the retina. In this way, the retina is provided with two opportunities to catch and absorb the light entering the eye. Nocturnal animals or species inhabiting dark environments typically possess this structure, which is thought to improve vision in low light conditions (Ollivier et al. 2004). The detection of a tapetum lucidum in the chamois eye supports behavioural data that chamois, although largely diurnal, are also night-active (Ingold et al. 1998).

\section{Responses of chamois to hikers}

The two response variables measured during the behavioural experiments (alert distance and flight initiation distance) are likely to reflect different stages of response to potential predators (Schnidrig-Petrig and Ingold 2001). Firstly, alert distance reflects the moment of detection of the potential threat. This variable should be correlated with how conspicuous the approaching threat is. Therefore, in the context of our experiments, it would be expected that differences in alert distances in response to the conspicuousness of different jackets would be detected. Similarly, flight distances may be longer for more conspicuous colours as hikers are presumed to be visible at greater distances, and hence, for longer periods of time during the flight response of the chamois. Despite these predictions, we detected no difference in the chamois alert and flight initiation distance to the various jacket colours. Although it was not possible in this study to quantify the conspicuousness of the three coloured coats relative to chamois vision, it is at least likely that the azure blue coat is less conspicuous than the yellow coat, given that hikers approached the chamois with a sky blue background. The red coat may also have been inconspicuous, given the lack of long-wavelength-sensitive cones in the chamois eye. The lack of difference in alert distance suggests that it may be movement, instead of conspicuousness per se, that alerts the animals to potential threats. Therefore, if chamois detect the person on the basis of movement rather than colour, then any effect of raincoat colour or brightness would be masked by movement of the hiker.

Our results support a study by Schnidrig-Petrig and Ingold (2001), which demonstrated that neither the colour nor brightness of paragliders had an effect on the alert reactions of chamois. It therefore appears that our findings are a general trend, in which colours in leisure sport clothes do not affect the chamois. This is in contrast to other disturbances which are known to affect chamois, such as loud voices (Kobelt, 2004) or large group sizes, mountain biking, cross-country hiking, snowmobiles, cross-country skiing, aircrafts and approaches from unexpected locations (Frid 2003; Naylor et al. 2009; Neumann et al. 2010; Reimers et al. 2003; Stankowich 2008). However, our data do indicate that disturbances by humans are costly to the chamois. For example, the chamois still covered relative long and hilly distances to their refuge site after the approach by the hiker. Along with the increased energetic costs and stress associated with this flight response, leaving the salt lick may also be costly in itself (see below). The flight response may also affect the chamois' feeding activity (Cederna and Lovari 1985; Hamr 1988).

In addition to the lack of difference in the response to different coloured rain coats, we also found no affect on the group size or presence of kids. The former result is consistent with the findings by Bäbler (2001), but contrasts with those by Cederna and Lovari (1985) who showed that chamois have a more reactive flight response when in smaller group sizes. This lack of consensus between studies indicates that additional factors may influence how vigilant animals are in different group sizes (e.g. presence of obstructions: Harkin et al. 2000; reproductive state; Klose et al. 2009). For example, in contrast to our results, Patterson (1988) showed that grazing females with kids initiated a flight response at a greater distance from the threat compared to females without kids.

Despite following a standard protocol to measure flight response, our data need to be interpreted with some caution, as several factors may have masked the effects of raincoat colouration on the animals' response. For example, the study was conducted during a summer period which was uncharacteristically hot. The experimental lick was one of the very few in the area that had not completely desiccated. Therefore, it was an extremely valuable resource for the chamois, especially for females with kids. Due to the potentially high costs of leaving the salt lick, animals may have stayed at the lick for as long as possible. Our observation that several chamois did not take flight from the approaching person towards the end of the season supports this hypothesis (S. Raveh, personal observation). Several studies in other taxa have found that the increased costs of leaving a feeding site influences flight behaviour (Bellman and Krasne 1983; Cooper 2000; Cooper et al. 2003; Krause and Godin 1996; Scrimgeour and Culp 1994; Stankowich and Blumstein 2005; Tyler 1991). Thus, a female's decisionmaking may vary with season due to different 
environmental and individual conditions and thereby influence risk sensitivities and decision rules (Stankowich 2008). However, this could not explain why we found no differences in the alert distances between colours. The lick was located in an area where few tourist activities occur and where hunting is not permitted. This may influence the behaviour of the chamois in this area as hunted populations show significantly greater flight responses than nonhunted populations (Stankowich 2008). Although we measured flight responses of females in an area containing licks, repeating the study in other contexts (e.g. in pastures where animals are grazing or flight responses of males) may well prove to be illuminating. For example, Dalmau et al. (2010) showed that males are more vigilant than females in the closely related Pyrenean chamois (Rupicapra pyrenaica pyrenaica). In addition, repeating the study using natural greens and browns normally worn by hunters could provide a more complete picture of how clothing affects the behaviour of wildlife. Combining our findings with such additional experiments would be integral to state conclusively that colour plays no role in the fear response of chamois and to allow appropriate formulation of tourism management strategies.

Acknowledgments We thank the Canton Bern and the Jagdinspektorat for generously providing the hunting lodge and the Jagdinspektor P. Juesy and the gamekeepers R. Fuchs and P. Schwendimann for providing the eyes of the chamois. Furthermore, we thank the Bern University Hospital Department of Veterinary Medicine, M. Stoffel and his team for providing chemical additives, as well as K. Bennmann for the demonstration of eye enucleation. Thanks to Prof. Charlotte Remé (Dr. Med) and Andreas Wenzel (Dr. sc. nat.) of the Department of Ophthalmology, University of Zurich for the examination of the chamois retinas and their suggestions for this paper and also to Jeremy Nathans (Johns Hopkins, Baltimore, USA) for generously supplying the primary antibodies. We are grateful to J.-P. Airoldi's statistical help, as well as to C. Raaflaub, A. Imhasly, P. Enggist, T. Karels, R. Bergmüller, S. Kenyon, A. Nesterova and the AEN team's comments on the manuscript.

\section{References}

Albrecht L (1988) Habituation von Gemsen Rupicapra rupicapra an den Menschen. Master. University of Zurich, Switzerland

Arlettaz R, Patthey P, Baltic M, Leu T, Schaub M, Palme R, Jenni-Eiermann S (2007) Spreading free-riding snow sports represent a novel serious threat for wildlife. Proc R Soc Lond B Biol Sci 274:1219-1224

Arrese CA, Hart NS, Thomas N, Beazley LD, Shand J (2003a) Trichomacy in Australian marsupials. Curr Biol 12:657-660

Arrese CA, Rodger J, Beazley LD, Shand J (2003b) Topographies of retinal cone photoreceptors in two Australian marsupials. Visual Neurosci 20:307-311

Bäbler R (2001) Beeinflussen Jagd und Tourismus die Reaktionsempfindlichkeit von Gemsen (Rupicapra rupicapra)? Master. University of Bern, Switzerland

Bellairs R, Harkness ML, Harkness RD (1975) The structure of the tapetum of the eye of the sheep. Cell Tissue Res 157:73-91
Bellman KL, Krasne FB (1983) Adaptive complexity of interactions between feeding and escape in crayfish. Science 221:779-781

Birgersson B, Alm U, Forkman B (2001) Colour vision in fallow deer: a behavioural study. Anim Behav 61:367-371

Blanks JC, Johnson LV (1984) Specific binding of peanut lectin to a class of retinal photoreceptor cells: a species comparison. Invest Ophthalmol Vis Sci 25:546-557

Carroll J, Murphy CJ, Neitz M, Ver Hoeve JN, Neitz J (2001) Photopigment basis for dichromatic colour vision in the horse. $\mathrm{J}$ of vision 1:80-87

Cederna A, Lovari S (1985) The impact of tourism on chamois feeding activities in an area of the Abruzzo National Park, Italy. In: Lovari $\mathrm{S}$ (ed) The biology and management of mountain ungulates. T Croom Helm, London

Chiu MI, Nathans J (1994) Blue cones and cone bipolar cells share transcriptional specificity as determined by expression of human blue visual pigment-derived transgenes. J Neurosci 14:34263436

Cooper WE (2000) Tradeoffs between predation risk and feeding in a lizard, the broad-headed skink (Eumeces laticeps). Behaviour 137:1175-1189

Cooper WE Jr, Pérez-Mellado V, Baird T, Baird TA, Caldwell JP, Vitt LJ (2003) Effects of risk, cost, and their interaction on optimal escape by nonrefuging Bonaire whiptail lizards, Cnemidophorus murinus. Behav Ecol 14:288-293

Dalmau A, Ferret A, Manteca X (2010) Vigilance behavior of Pyrenean chamois Rupicapra pyrenaica pyrenaica: effect of sex and position in the herd. Curr Zool 56:232-237

Dkhissi-Benyahya O, Szel A, Degrip WJ, Cooper HM (2001) Short and mid-wavelength cone distribution in a nocturnal strepsirrhine primate (Microcebus murinus). J Comp Neurol 438:490-504

Doucet SM, Mennill DJ, Hill GE (2007) The evolution of signal design in manakin plumage ornaments. Amer Nat 169:S62-S80

Endler JA (1993) The color of light in forests and its implications. Ecol Monogr 63:1-27

Enggist-Düblin P, Ingold P (2003) Modelling the impact of different forms of wildlife harassment, exemplified by a quantitative comparison of the effects of hikers and paragliders on feeding and space use of chamois Rupicapra $r$ rupicapra. Wildlife Biol 1: $37-45$

Frid A (2003) Dall's sheep response to overflights by helicopter and fixed-wing aircraft. Biol Conserv 110:387-399

Gander H, Ingold P (1997) Reactions of male alpine chamois Rupicapra r. rupicapra to hikers, joggers and mountainbikers. Biol Conserv 9:107-109

Glosmann M, Ahnelt PK (2002) A mouse-like retinal cone phenotype in the Syrian hamster: $\mathrm{S}$ opsin coexpressed with $\mathrm{M}$ opsin in a common cone photoreceptor. Brain Res 929:139-146

Hack I, Peichl L (1999) Horizontal cells of the rabbit retina are non-selectively connected to the cones. Eur J Neurosci 11:2261-2274

Hageman GS, Johnson LV (1986) Biochemical characterization of the major peanut-agglutinin-binding glycoproteins in vertebrate retinae. J Comp Neurol 249(499-510):482-483

Hamr J (1988) Disturbance behaviour of chamois in an alpine tourist area of Austria. Mt Res Dev 8:65-73

Harkin EL, van Dongen WFD, Herberstein ME, Elgar MA (2000) The influence of visual obstructions on the vigilance and escape behaviour of house sparrows, Passer domesticus. Aust J Zool 48:259-263

Hemmi JM, Grünert U (1999) Distribution of photoreceptors types in the retina of a marsupial, the tammar wallaby (Macropus eugenii). Vis Neurosci 16:291-302

Hicks LL, Elder JM (1979) Human disturbance of Sierra Nevada bighorn sheep. J Wildlife Manage 43:909-915

Hüppop O (1995) Störungsbewertung anhand physiologischer Parameter. Ornithologischer Beobachter 92:257-268 
Ingold P (2005) Freizeitaktivitäten im Lebensraum der Alpentiere: Konfliktbereiche zwischen Mensch und Tier. Mit einem Ratgeber für die Praxis, Haupt, Verlag

Ingold P, Pfister U, Baechler E, Enggist-Dueblin P (1998) Pattern and rhythm of activity in alpine chamois Rupicapra $r$. rupicapra during winter. Z. Säugetierkd 63:183-185

Jacobs GH (1981) Comparative colour vision. Academic Press, New York

Jacobs GH (1993) The distribution and nature of colour vision among the mammals. Biol Rev 68:413-471

Jacobs GH (2009) Evolution of colour vision in mammals. Philos Trans R Soc Lond B Biol Sci 364:2957-2967

Jacobs GH, Deegan JF II, Crognale MA, Femwick JA (1993) Photopigments of dogs and foxes and their implications for canid vision. Vis Neurosci 10:173-180

Jacobs GH, Deegan JF II, Neitz J, Murphy BP, Miller KV, Marchinton RL (1994) Electrophysiological measurements of spectral mechanisms in the retina of two cervids: white-tailed deer (Odocoileus virginianus) and fallow deer (Dama dama). J Comp Neurol 174:551-557

Jacobs GH, Deegan JF II, Neitz J (1998) Photopigment basis for dichromatic colour vision in cows, goats, and sheep. Vis Neurosci 15:581-584

Kaskan PM, Franco ECS, Yamada ES, Silveira LC, Darlington RB, Finlay BL (2005) Peripheral variability and central constancy in mammalian visual system evolution. Proc R Soc B 272:91-100

Keller V (2001) Schutzzonen für Wasservögel-Grundsätze und Erfahrungen aus der Schweiz. Laufener Seminarbeiträge 1(01):83-86

Klose S, Welbergen J, Goldizen A, Kalko E (2009) Spatio-temporal vigilance architecture of an Australian flying-fox colony. Behav Ecol Sociobiol 63:371-380

Koba Y, Tanida H (1999) How do miniature pigs discriminate between people? The effect of exchanging cues between a non-handler and their familiar handler on discrimination. Appl Anim Behav Sci 61:239-252

Kobelt M (2004) Reactions of alpine chamois Rupicapra rup. rupicapra to human voices. Master. University of Bern, Switzerland

Krause J, Godin JGJ (1996) Influence of prey foraging posture on flight behavior and predation risk: predators take advantage of unwary prey. Behav Ecol 7:264-271

Krishnamoorthy V, Jain V, Cherukuri P, Baloni S, Dhingra NK (2008) Intravitreal injection of fluorochrome-conjugated peanut agglutinin results in specific and reversible labeling of mammalian cones in vivo. Invest Ophthalmol Vis Sci 49:2643-2650

MacArthur RA, Geist V, Johnston RH (1982) Cardiac and behavioural responses if mountain sheep to human disturbance. J Wildlife Manage 46:351-358

Mainini B, Neuhaus P, Ingold P (1993) Behaviour of marmots Marmota marmota under the influence of different hiking activities. Biol Conserv 64:161-164

Marbacher H (1989) Soziale Organisation und Konkurrenz in einer Herde von jungeführenden Gemsgeissen Rupicapra rupicapra. Master. University of Bern, Switzerland

Martin PR, Grünert U (1999) Analysis of the short-wavelength sensitive ("blue") cone mosaic in the primate retina: comparison New World and Old World monkeys. J Comp Neurol 406:1-14

Martinetto K, Cugnasse JM (2001) Reaction distance in Mediterranean Mouflon (Ovis gmelini musimon x Ovis sp.) in the presence of hikers with a dog on the Caroux plateau (Herault, France). Revue D Ecologie-la Terre Et La Vie 56:231-242
Munkenbeck NW (1982) Colour vision in sheep. J Anim Sci 55 (suppl1):129

Naylor LM, Wisdom MJ, Anthony RG (2009) Behavioural responses of North American elk to recreational activity. J Wildlife Manage 73:328-338

Neumann W, Ericsson G, Dettki H (2010) Does off-trail backcountry skiing disturb moose? Eur J Wildlife Res 56:513-518

Ollivier FJ, Samuelson DA, Brooks DE, Lewis PA, Kallberg ME, Komáromy AM (2004) Comparative morphology of the tapetum lucidum (among selected species). Vet Ophthalmol 7:11-22

Patterson IJ (1988) Response of Apennine chamois to human disturbance. Z. Säugetierkd 53:245-252

Reimers E, Eftestol S, Colman JE (2003) Behavior responses of wild reindeer to direct provocation by snowmobile or skier. J Wildlife Manage 67:747-754

Robbins CT (1993) Wildlife feeding and nutrition. 2nd ed. Academic Press, Inc. San Diego, California

Ruckstuhl KE, Ingold P (1998) Baby-sitting in chamois: a form of cooperation in females? Mammalia 62:125-128

Sandmann D, Boycott BB, Peichl L (1996) Blue-cone horizontal cells in the retinae of horses and other Equidae. J Neurosci 16:3381-3396

Schaal A, Boillet F (1992) Chamois and human disturbance in the Vosges mountains. In: Spitz, F., Janeau, G., Gonzalez, G., Aulanger (eds) Toulouse. Ongulés Ungulates 91, Proc. int. symp. S. 639-642.

Schnidrig-Petrig R (1994) Modern icarus in wildlife habitat: effects of paraglidering on the behaviour, habitat use and body condition of chamois (Rupicapra r. rupicapra). Dissertation. University of Bern, Switzerland

Schnidrig-Petrig R, Ingold P (2001) Effects of paragliding on chamois Rupicapra r. rupicapra. Wildlife Biol 7:285-294

Schröder W, Elsner-Schack I (1985) Correct age determination in chamois. In: Lovari S (ed) Biology and management of mountain ungulates. Croom Helm, London, pp 65-70

Scrimgeour GJ, Culp JM (1994) Feeding while evading predators by a lotic mayfly: linking short-term foraging behaviours to long-term fitness consequences. Oecologia 100:128-134

Siemers B, Backhaus W, Franz H (1999) Colour vision in farm animals: evidence for trichromacy in dwarf goats. Proceedings of the 27th neurobiology conference (Göttingen), Georg Thieme Verlag Stuttgart, NY.

Stankowich T (2008) Ungulate flight responses to human disturbance: a review and meta-analysis. Biol Conserv 141:2159-2173

Stankowich T, Blumstein DT (2005) Fear in animals: a meta-analysis and review of risk assessment. Proc R Soc B 272:2627-2634

Taylor AR, Knight RL (2003) Wildlife responses to recreation and associated visitor perceptions. J Appl Ecol 13:951-963

Tyler NC (1991) Short-term behavioural responses of Svalbard reindeer Rangifer tarandus platyrhynchus to direct provocation by a snowmobile. Biol Conserv 56:179-194

Unoki K, Uehara F, Sameshima M, Nakano K, Ohba N (1988) Specific binding of peanut agglutinin to foveal and peripheral cone photoreceptors of monkey retina. Ophthalmic Res 20:112-116

Wikler KC, Szel A, Jacobsen AL (1996) Positional information and opsin identity in retinal cones. J Comp Neurol 374:96-107

Zeller R (1991) Zum Verhalten von Gemsgeissen unter dem Einfluss von

Zimmerli R (1993) Das Verhalten von Murmeltieren unter dem Einfluss eines unterschiedlich starken Wanderbetriebes: Aspekte der Nahrungsaufnahme und der Gebietsnutzung. Master. University of Bern, Switzerland 